\section{Revista de CIENCIAS AMBIENTALES Tropical Journal of Environmental Sciences}

Revista de Ciencias Ambientales (Trop J Environ Sci)

e-ISSN: 2215-3896

(Julio-Diciembre, 2020) . Vol 54(2): 51-67

DOI: https://doi.org/10.15359/rca.54-2.3

Open Access: www.revistas.una.ac.cr/ambientales

e-mail: revista.ambientales@una.ac.cr

Ramón-Puebla A., Yandy Rodríguez-Cueto Y.

\title{
Propuesta de rutas de conectividad para la conservación de la biodiversidad en Sierra Maestra, Cuba
}

\author{
A Proposal of Connectivity Routes for Biodiversity Conservation in Sierra Maestra, \\ Cuba
}

\author{
Adonis Ramón Puebla ${ }^{1}$, Yandy Rodríguez Cueto ${ }^{2}$, Pedro M. Álvarez-Amargos ${ }^{3}$
}

[Recibido: 28 de febrero 2020, Aceptado: 10 de mayo 2020, Corregido: 20 de mayo 2020, Publicado: 1 de julio 2020]

Resumen

[Introducción]: Una de las estrategias para fomentar el mantenimiento de la biodiversidad en el nivel de paisaje, es el establecimiento de rutas de conectividad estructural entre las áreas núcleo de conservación ecológica. Sin embargo, el diseño de áreas protegidas en Cuba ha carecido del establecimiento de redes que sirvan de enlace entre estas áreas. [Objetivo]: En esta investigación, se desarrolla una propuesta teórica de rutas de conectividad entre las 19 áreas protegidas de categoría de conservación más estricta de la Sierra Maestra. [Metodología]: Se desarrolla un modelo de costo-distancia en ArcGIS con base en un mapa de fricción o resistencia al desplazamiento, elaborado a partir de la selección y la evaluación de un grupo de criterios para establecer los niveles de dificultad para la conectividad en función de la pendiente del terreno, la cobertura del suelo, la red hídrica y vial, y la distribución de los asentamientos poblacionales. [Resultados]: Se obtuvo mediante el modelaje el trazado de 186 rutas de conectividad estructural, clasificadas en 114 rutas altitudinales y 72 longitudinales que permiten la conexión entre áreas protegidas a diferentes pisos altitudinales. Además, se encuentran 53 zonas de interés para la biodiversidad al ser cruzadas por varias rutas. [Conclusiones]: La metodología diseñada recoge la mayoría de los elementos que pueden incidir en la conectividad de espacios naturales a nivel local y regional, por tanto, contribuye de manera central en las tareas de planificación y ordenamiento territorial.

Palabras claves: Áreas protegidas; mapa de fricción; modelo costo-distancia rutas de conectividad estructural; sistema de información geográfica.

\begin{abstract}
[Introduction]: One of the strategies to promote the maintenance of biodiversity at the landscape level is the establishment of structural connectivity routes between the core areas of ecological conservation. However, the design of protected areas in Cuba has lacked the establishment of connectivity networks that serve as links between those areas. [Objective]: This research proposes a theoretical design of connectivity routes between the 19 most stringent conservation protected areas of the Sierra Maestra. [Methodology]: Based on terrain slope, land cover, water network, road network, and density of population settlement, friction or resistance to displacement map is computed. [Results]: The Cost-distance model, from ArcGIS, identifies the total amount of 186 structural

1 Especialista en Ciencia, Tecnología y Medio Ambiente, Órgano de Montaña Sierra Maestra, Cuba; adonis.maikel@gmail.com; https://orcid. org/0000-0002-2515-2508

2 Ingeniero civil, investigador agregado, Centro de Investigaciones de Ecosistemas Costeros, Cuba; yandyro84@gmail.com; https://orcid. org/0000-0002-1792-6737

3 GIS Technician, City of McKinney, Texas, USA; pmartin.alv75@gmail.com; https://orcid.org/0000-0001-5396-7045
\end{abstract}

(cc)




\section{Revista de CIENCIAS AMBIENTALES Tropical Journal of Environmental Sciences}

Revista de Ciencias Ambientales (Trop J Environ Sci) e-ISSN: 2215-3896

(Julio-Diciembre, 2020) . Vol 54(2): 51-67 DOI: https://doi.org/10.15359/rca.54-2.3 Open Access: www.revistas.una.ac.cr/ambientales e-mail: revista.ambientales@una.ac.cr Ramón-Puebla A., Yandy Rodríguez-Cueto Y. y Álvarez-Amargos P.

connectivity routes. [Conclusions]: Altitudinal connectivity routes, allowing the connection between protected areas to different altitudinal floors, include 114 routes, while longitudinal connectivity, allowing the connection between protected areas to the same altitudinal level, includes 72 routes. Route density allows the identification of 53 areas of interest for biodiversity.

Keywords: Cost-distance model; friction map; geographic information system; protect areas; structural connectivity routes.

\section{Introducción}

La manera más eficaz para conservar la biodiversidad ha sido tradicionalmente concebida a través de los sistemas de áreas protegidas; pero, a pesar de las ventajas de las áreas protegidas, la falta de conectividad entre éstas puede dar al traste con el objetivo fundamental de su creación, que es la conservación de los atributos naturales de la región. A pesar de que, desde hace varias décadas, las estrategias internacionales para la conservación de la biodiversidad reconocen la necesidad de mantener los sistemas ecológicos conectados, según la teoría del equilibrio de biogeografía de islas postulada por MacArthur y Wilson (1967), dicha conexión se fundamenta, según Primack et al. (2001), en la existencia de rutas de conectividad, con base en el supuesto de que los fragmentos conectados por un corredor disminuyen la tasa de extinción y contribuyen a un mayor valor para la conservación en comparación con los hábitats aislados.

El concepto de conectividad se refiere a la conexión de hábitats, especies, comunidades y procesos ecológicos (Noss, 1991); se emplea, comúnmente, para describir cómo los arreglos espaciales y la calidad de los elementos en el paisaje afectan el desplazamiento de organismos entre fragmentos de hábitats. Para Bennett (2004), la fragmentación de los hábitat es la responsable directa de la capacidad disminuida de los animales y plantas de desplazarse por el paisaje, lo cual tiene una serie de consecuencias importantes sobre las especies: las limita en su capacidad de suplir poblaciones en disminución; de recolonizar hábitats donde se han producido extinciones derivadas de incendios, inundaciones $u$ otras afectaciones de origen natural o antrópico; de colonizar nuevos hábitats adecuados, y según Chacón (2016), también disminuye la opción de escape hacia zonas más elevadas por posibles cambios de las condiciones ecológicas por el cambio climático.

Miller et al. (2001) y Bennett y Mulongoy (2006) argumentan que, en todos los estudios de los procesos ecológicos y de dispersión de las especies en un paisaje, es posible aplicar los modelos de conectividad para generar redes de conectividad estructural, considerándose estas mismas como una estructura espacial que pretende fungir como enlace entre zonas núcleo, por lo general áreas protegidas, cuya trayectoria está definida por las rutas que generan una menor resistencia al movimiento de especies. Estas redes, afirma Hoctor et al. (1999), se pueden diseñar a partir de modelos que producen escenarios gráficos sobre la permeabilidad del paisaje, en función de la distancia máxima de dispersión ecológica contra la resistencia ejercida por el uso del suelo.

\begin{tabular}{|c|c|c|c|c|c|}
\hline 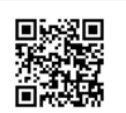 & (c) & $\overbrace{\text { AMEIENTILES }}$ & $\frac{9 \%}{20}$ & $\frac{\text { UNA }}{\frac{\text { UNIVERIDAD }}{\text { NACIONAL }}}$ & 52 \\
\hline
\end{tabular}




\section{Revista de CIENCIAS AMBIENTALES Tropical Journal of Environmental Sciences}

Revista de Ciencias Ambientales (Trop J Environ Sci) e-ISSN: $2215-3896$

(Julio-Diciembre, 2020) . Vol 54(2): 51-67 DOI: https://doi.org/10.15359/rca.54-2.3 Open Access: www.revistas.una.ac.cr/ambientales e-mail: revista.ambientales@una.ac.cr Ramón-Puebla A., Yandy Rodríguez-Cueto Y. y Álvarez-Amargos P.

De acuerdo con Parrish et al. (2003), la conectividad se relaciona con el acceso de las diferentes especies a todos los hábitats y recursos necesarios para completar sus ciclos de vida, así como con la capacidad de movimiento, en caso de cambios abruptos en factores ecológicos. De esta forma, parece claro que la conectividad se convierte en un factor indispensable para el mantenimiento de los procesos ecológicos y poblaciones de especies en la planificación sistemática y estratégica; sobre todo, en paisajes vulnerables al impacto humano o donde la integridad ecológica no se encuentre en los rangos de variación aceptable. Es entonces cuando mantener y restaurar la conectividad ecológica como atributo clave en la funcionalidad de los ecosistemas debe ser una meta de los esfuerzos de planificación de sistemas de áreas protegidas y de estrategias nacionales de conservación de la biodiversidad, y para el mantenimiento de los bienes y servicios ecosistémicos asociados.

Cuba, a pesar de contar con una amplia red de áreas protegidas que va desde las zonas marino-costeras hasta las montañas más elevadas del país; como sistema carece de un necesario diseño e implementación de rutas de conectividad que permita la movilidad de especies y el correspondiente flujo genético entre estas mismas. Al hablar de un sistema, lo relacionamos inmediatamente con conceptos como: función, enlaces y orden, los que son, por lógica, condiciones básicas de su composición. Por lo tanto, un sistema de áreas protegidas debe contar, de forma óptima, con unidades territorialmente conectadas entre ellas. De esta forma, si comprendemos que el sistema es el modo mediante el cual puede protegerse, de manera formal, la biodiversidad, ya fuertemente intervenida y fragmentada por la actividad antrópica, este debe contener mecanismos de conexión; definidas según EUROPAC (2009) como la propiedad del paisaje que hace posible el flujo de materia, energía y organismos entre diversos ecosistemas, hábitats o comunidades.

En este contexto, los sistemas montañosos cubanos, caracterizados según Duran et al. (2000) por una alta complejidad y fragilidad geoecológica, ser relativamente de baja altitud (valores de altitud inferiores a los $2000 \mathrm{~m}$ ), y una extensión limitada a no más del $30 \%$ de la superficie del país, constituyen los núcleos de origen de la flora y fauna actual de Cuba y sus principales relictos. Éstos no han escapado de la fragmentación provocada por los cambios a que han sido sometidos por la actividad humana a lo largo de la historia; con un claro predominio en su asimilación de un uso irracional; con prácticas agrícolas inadecuadas, y una excesiva explotación de los recursos forestales. Todo ello ha conllevado a la existencia actual de grandes áreas deforestadas y convertidas en zonas ganaderas, algunas ya abandonadas, en distintos estadios de regeneración natural y otras con presencia de diversos cultivos que, de forma general, provocan una pérdida y degradación acelerada de los suelos y de los restantes componentes naturales.

No obstante, lo expuesto por Duran et al. (2000), aún subsisten, en las zonas montañosas, áreas de vegetación natural y seminatural con mayor o menor grado de fragmentación, que componen hoy los principales núcleos de conservación de la biodiversidad y constituyen la base de gran parte del Sistema Nacional de Áreas Protegidas, donde se manifiesta la carencia de un sistema de conectividad entre estas áreas protegidas. Esta conectividad sólo comienza a

\begin{tabular}{|c|c|c|}
\hline 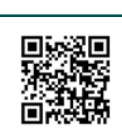 & (c) (i) () (2) & 53 \\
\hline
\end{tabular}




\section{Revista de CIENCIAS AMBIENTALES Tropical Journal of Environmental Sciences}

Revista de Ciencias Ambientales (Trop J Environ Sci) e-ISSN: 2215-3896

(Julio-Diciembre, 2020) . Vol 54(2): 51-67 DOI: https://doi.org/10.15359/rca.54-2.3 Open Access: www.revistas.una.ac.cr/ambientales e-mail: revista.ambientales@una.ac.cr Ramón-Puebla A., Yandy Rodríguez-Cueto Y. y Álvarez-Amargos P.

realizarse experimentalmente entre algunas áreas protegidas de algunos de los macizos montañosos del país, a partir de la implementación del proyecto del GEF-PNUD Conectando Paisajes.

Un ejemplo de lo ya descrito es el macizo montañoso Sierra Maestra, el cual, valga aclarar, no se encuentra dentro del proyecto Conectando Paisajes, y es uno de los principales grupos montañosos de Cuba, con remanentes de bosques naturales y seminaturales, que constituyen, en lo fundamental, las principales áreas protegidas de la región sur oriental del país, rodeadas de ambientes alterados por zonas forestales, agrícolas, pastizales y urbanas. Se limita, así, su posibilidad de mantener la biodiversidad por sí solas como "islas", por lo que se impone, a partir de lo planteado por Bennett y Mulongoy (2006), la necesidad de una red de hábitats intercomunicados que mantenga la conectividad de los procesos ecológicos y las poblaciones de especies.

Considerando el panorama anterior, esta investigación se plantea dos objetivos principales: a) Identificar criterios para establecer los niveles de dificultad para conectividad por los tipos de cobertura y por las actividades que existan o se desarrollen en el territorio, en zonas ubicadas entre áreas naturales protegidas. b) Desarrollar una metodología válida para zonas montañosas, que contribuya al trazado de rutas de conectividad entre las áreas protegidas y sus zonas adyacentes, y que, a su vez, pueda servir de base para el diseño de futuros corredores biológicos para este territorio.

\section{Metodología}

Para cumplir los objetivos de este trabajo se planteó una estrategia metodológica a partir de dos elementos fundamentales: primeramente, la selección y evaluación de los criterios por grupos expertos para establecer los niveles de dificultad para la conectividad; y segundo, el diseño de las rutas de conectividad entre las áreas protegidas de categorías de conservación más estrictas en la Sierra Maestra, mediante un modelo de sistema de información geográfica de costo-distancia y con base en la elaboración de un mapa de resistencias al desplazamiento (rutas de máxima conectividad o permeabilidad del paisaje entre espacios-núcleo).

\section{1 Área de estudio}

La Sierra Maestra, localizada en la parte suroccidental de la región oriental de Cuba (Figura 1), limita al norte con la cuenca del río Cauto y la depresión tectónica del Valle Central; al sur con la Fosa de Bartlett; al este con la cuenca de Guantánamo y al oeste con la llanura costera que la separa del Golfo de Guacanayabo.

\begin{tabular}{|c|c|c|c|c|c|}
\hline 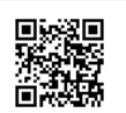 & (c) & $\overbrace{\text { AMEIENTILES }}$ & $\frac{9 \%}{20}$ & $\frac{\text { UNA }}{\frac{\text { UNIVERSIIDAD }}{\text { NACIONAL }}}$ & 54 \\
\hline
\end{tabular}




\section{Revista de \\ CIENCIAS AMBIENTALES Tropical Journal of Environmental Sciences}

Revista de Ciencias Ambientales (Trop J Environ Sci)

e-ISSN: 2215-3896

(Julio-Diciembre, 2020) . Vol 54(2): 51-67

DOI: https://doi.org/10.15359/rca.54-2.3

Open Access: www.revistas.una.ac.cr/ambientales e-mail: revista.ambientales@una.ac.cr Ramón-Puebla A., Yandy Rodríguez-Cueto Y. y Álvarez-Amargos P.

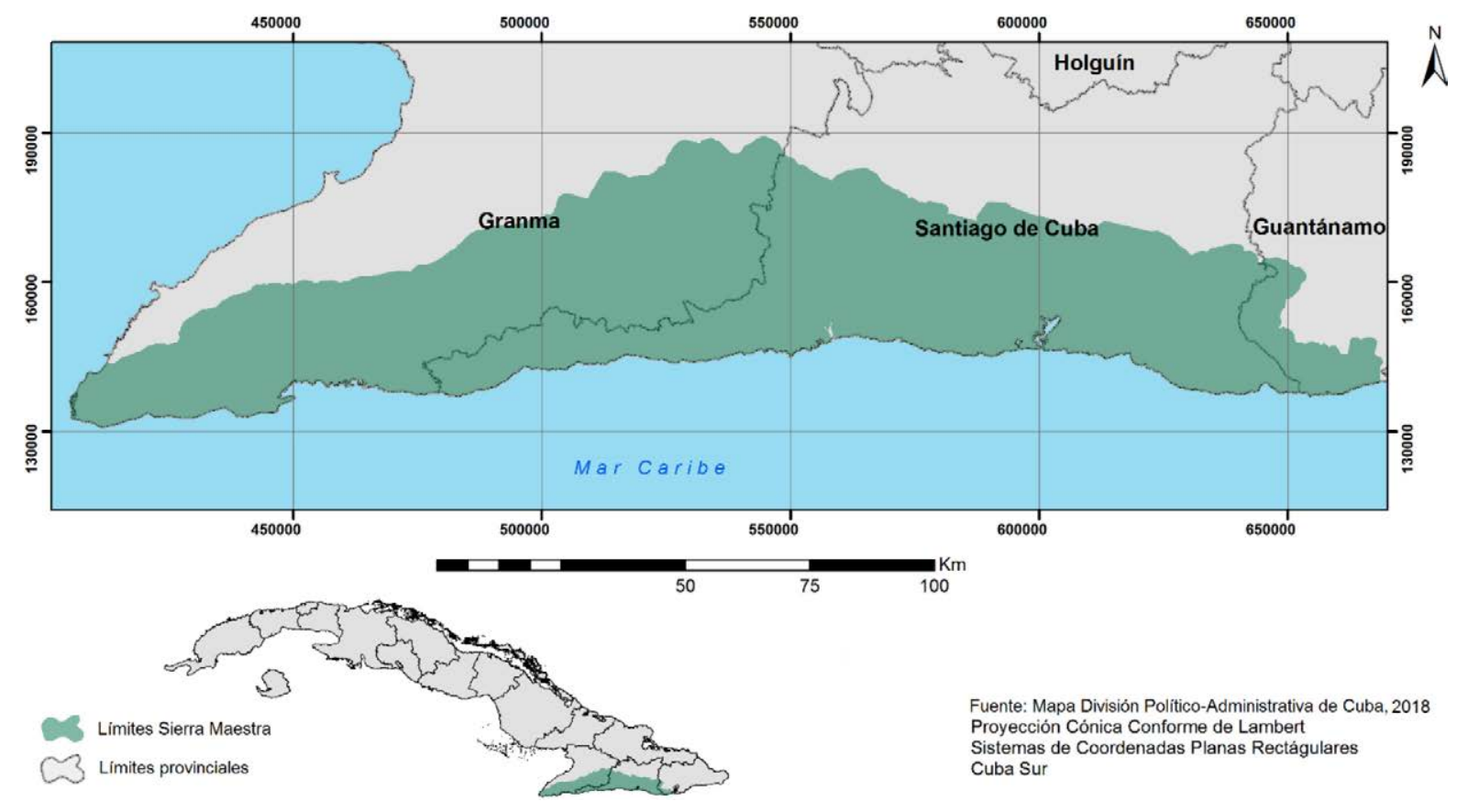

Figura 1. Localización de la Sierra Maestra.

Figure 1. Sierra Maestra Location.

En este grupo montañoso, Viña et al. (2000) refieren que es donde la zonalidad vertical se manifiesta más marcadamente en Cuba. Por ello, allí aparecen las formaciones vegetales divididas en pisos altitudinales. En esta zona se manifiesta, además, una fuerte diferenciación climática entre las laderas norte y sur, que, dada la dirección predominante de los vientos alisios del NE y la orientación E-O de la sierra, provoca la existencia de una vertiente meridional seca y un septentrional húmeda. Estas características, más otras, derivadas de poseer las mayores alturas del país, un mosaico variado de suelos, litologías y un importante patrimonio forestal, le han proporcionado altos valores de diversidad biológica.

Todo este patrimonio y valores de diversidad biológica anteriormente mencionados se encuentran asegurados por 19 parches dispersos de áreas protegidas de diversos tamaños y categorías, que cubren los remanentes mejor conservados de bosques naturales y seminaturales, concentrados en lo fundamental hacia los extremos y zona central del macizo, y en su porción centro sur. Estos parches, en sus categorías de conservación más estrictas, cubren aproximadamente el $13 \%$ del territorio y resguardan el $10.5 \%$ de los bosques naturales mejor conservados de la zona.

Este mosaico de áreas protegidas carece, actualmente, de un sistema de interconexión que permita el flujo entre ellas, pues sólo en 3 de los casos, las áreas protegidas poseen fronteras comunes y de estas una es por vía marina, el resto se encuentra a distancias que van desde los $4 \mathrm{~km}$ hasta más de $30 \mathrm{~km}$. Esto evidencia un relativo aislamiento entre las áreas protegidas, sobre todo

\begin{tabular}{|c|c|c|c|c|c|}
\hline 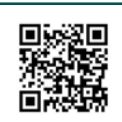 & (c) (i) () (2) & 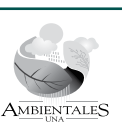 & $\frac{2 \%}{20}$ & 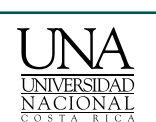 & 55 \\
\hline
\end{tabular}




\section{Revista de CIENCIAS AMBIENTALES Tropical Journal of Environmental Sciences}

Revista de Ciencias Ambientales (Trop J Environ Sci) e-ISSN: 2215-3896

(Julio-Diciembre, 2020) . Vol 54(2): 51-67 DOI: https://doi.org/10.15359/rca.54-2.3 Open Access: www.revistas.una.ac.cr/ambientales e-mail: revista.ambientales@una.ac.cr Ramón-Puebla A., Yandy Rodríguez-Cueto Y. y Álvarez-Amargos $P$.

las que se encuentran en las zonas hipsométricamente más bajas, las cuales son, además, más pequeñas en extensión que las que se encuentran en las zonas más altas; que se corresponden, de forma general, con los parches de mayores dimensiones y mayor diversidad ecológica. Además de existir un aislamiento relativo de las áreas protegidas entre la porción occidental y oriental del macizo montañoso (Figura 2).

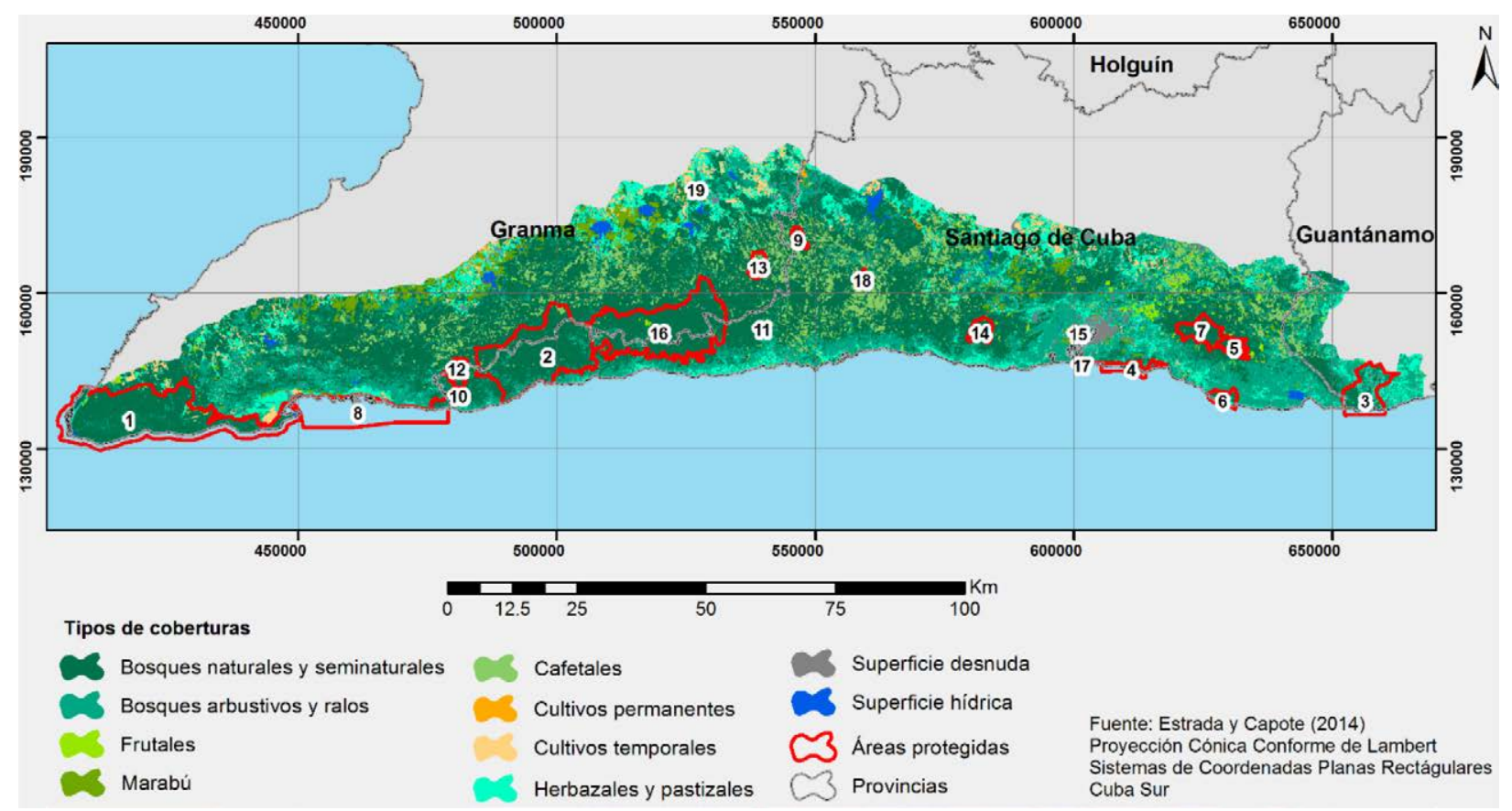

Figura 2. Distribución de la cobertura y áreas protegidas en la Sierra Maestra.

Figure 2. Distribution of the coverage and protected areas in Sierra Maestra.

\subsection{Modelo de diseño de las redes de conectividad ecológica}

Uno de los modelos más usados para el diseño de la red de conectividad estructural es el de Hoctor et al. (1999) y Céspedes et al. (2008), que plantea tres componentes fundamentales para el diseño de una red de conectividad estructural: a) Identificación de áreas protegidas a conectar y núcleos de hábitat prioritarios para la conservación que no están protegidos dentro del sistema nacional de áreas protegidas; b) Establecimiento de niveles de dificultad al desplazamiento de las especies silvestres en toda el área intermedia entre las áreas protegidas identificadas como objetivo; c) Modelación de la red de conectividad integrada por los núcleos prioritarios para la conservación, a través de las rutas de menor dificultad al desplazamiento.

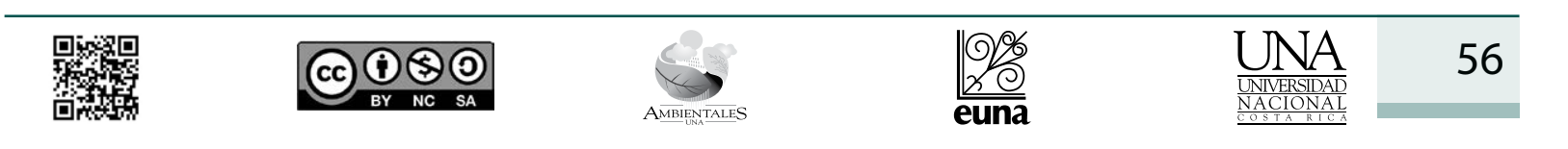




\section{Revista de CIENCIAS AMBIENTALES Tropical Journal of Environmental Sciences}

Revista de Ciencias Ambientales (Trop J Environ Sci) e-ISSN: 2215-3896

(Julio-Diciembre, 2020) . Vol 54(2): 51-67 DOI: https://doi.org/10.15359/rca.54-2.3 Open Access: www.revistas.una.ac.cr/ambientales e-mail: revista.ambientales@una.ac.cr Ramón-Puebla A., Yandy Rodríguez-Cueto Y. y Álvarez-Amargos P.

\subsubsection{Identificación de áreas protegidas a conectar}

Como áreas núcleo se consideran los remanentes de hábitat naturales con distintos grados de conservación que se interconectarán en el diseño de las rutas de conectividad. Para efectos de este trabajo, se seleccionaron las áreas protegidas de categorías de conservación más estrictas, con objetivos de manejo equivalentes a las categorías I y II de UICN. Estos sitios, 19 en total, son, en su mayoría: reservas naturales, parques nacionales, reservas ecológicas, elementos naturales destacados, reservas florísticas manejadas, refugios de fauna y paisajes naturales protegidos; áreas que por su categoría internacional y legislación nacional son propiedad estatal para ser protegidas con fines de conservación de la biodiversidad a perpetuidad.

\subsubsection{Establecimiento de niveles de dificultad al desplazamiento}

La dificultad para lograr la conectividad entre fragmentos boscosos está determinada por los tipos de cobertura y por las actividades que existan o se desarrollen en el territorio. La dificultad más alta la imponen aquellas áreas donde la cobertura existente o las actividades que se desarrollan se alejan más de las condiciones naturales. Así, por ejemplo, las áreas con concentraciones de asentamientos humanos, población o con zonas de alto tránsito vehicular o humano son las que imponen las dificultades más altas; mientras que las áreas de cobertura natural inalterada, sin presencia de centros de población, son las que menos dificultades imponen.

Los valores de dificultad fueron determinados con base en el análisis de cinco factores: cobertura del suelo, hidrografía, densidad de poblados, red vial y pendientes del terreno. Estos factores y sus escalas de valores fueron elaborada a partir de criterios y experiencias de personas expertas nacionales e internacionales consultadas en bibliografías referidas al tema, tales fueron los casos de: Jiménez (2001); Bennet (2004); Arias et al. (2008); y apoyados en los estudios de la biodiversidad de Cuba de: Mujica (2010); Borroto-Páez y Mancina (2011); y Mancina y Cruz (2017). Adicionalmente, se establecieron niveles jerárquicos y pesos ponderados para cada uno de los componentes incluidos en el análisis. La posición jerárquica que ocupa cada componente se estableció con base en su nivel de importancia relativa o nivel de significación que tiene uno con relación a otro apoyado en la bibliografía citada anteriormente.

Los pesos de los criterios se toman en una escala ordinal de 0 a 1 y se calculan aplicando el método de clasificación conocido como método de la suma. El cálculo del peso ponderado se obtiene mediante la aplicación de la Ecuación 1, de la siguiente manera.

$$
W=(\mathrm{N}-\mathrm{R})+\frac{1}{\Sigma(\mathrm{N}-\mathrm{R}+1)}
$$

Donde:

$W$ : Peso ponderado del criterio

$\mathrm{N}$ : Cantidad de criterios considerados en el análisis

R: Posición jerárquica que ocupa el criterio

\begin{tabular}{|c|c|c|c|c|c|}
\hline 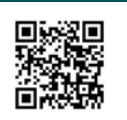 & (c) & $\overbrace{\text { AMBEDTALES }}^{3}$ & $\frac{10 \%}{\text { euna }}$ & 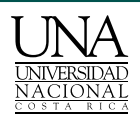 & 57 \\
\hline
\end{tabular}




\section{Revista de CIENCIAS AMBIENTALES Tropical Journal of Environmental Sciences}

Revista de Ciencias Ambientales (Trop J Environ Sci)

e-ISSN: 2215-3896

(Julio-Diciembre, 2020) . Vol 54(2): 51-67

DOI: https://doi.org/10.15359/rca.54-2.3

Open Access: www.revistas.una.ac.cr/ambientales

e-mail: revista.ambientales@una.ac.cr

Ramón-Puebla A., Yandy Rodríguez-Cueto Y.

y Álvarez-Amargos P.

Los criterios de reclasificación, así como de jerarquía y ponderación de cada componente, se presentan a continuación en el (Cuadro 1).

Cuadro 1. Categoría de la dificultad al desplazamiento establecida para cada clase

Table 1. Category of difficulty for displacement established for every class

\begin{tabular}{|c|c|c|c|c|c|c|c|}
\hline \multirow{2}{*}{ Componentes } & \multicolumn{5}{|c|}{ Categorías de dificultad al desplazamiento } & \multirow{2}{*}{ Jerarquía } & \multirow{2}{*}{ Peso } \\
\hline & 1 & 2 & 3 & 4 & 5 & & \\
\hline $\begin{array}{l}\text { Cobertura del } \\
\text { suelo }\end{array}$ & $\begin{array}{l}\text { Bosques } \\
\text { naturales } \\
\text { y poco } \\
\text { antropizados }\end{array}$ & $\begin{array}{l}\text { Bosques ralos, } \\
\text { secundarios, } \\
\text { cafetales y } \\
\text { frutales }\end{array}$ & $\begin{array}{l}\text { Herbazales y } \\
\text { pastizales con } \\
\text { parches de } \\
\text { árboles }\end{array}$ & $\begin{array}{l}\text { Cultivos } \\
\text { temporales }\end{array}$ & $\begin{array}{l}\text { Terreno } \\
\text { descubierto, y } \\
\text { grandes superficies } \\
\text { hídricas }\end{array}$ & 1 & 0.4 \\
\hline $\begin{array}{l}\text { Distancia a red } \\
\text { fluvial (metros) }\end{array}$ & menos de 15 & de 16 a 50 & de 51 a 100 & de 101 a 200 & mayor a 200 & 2 & 0.2 \\
\hline $\begin{array}{l}\text { Densidad de } \\
\text { puntos poblados }\end{array}$ & $0-0.168$ & $0.169-0.336$ & $0.337-0.504$ & $0.505-0.672$ & $0.673-0.840$ & 3 & 0.15 \\
\hline $\begin{array}{l}\text { Distancia a red } \\
\text { vial (metros) }\end{array}$ & mayor a 1001 & de 501 a 1000 & de 201 a 500 & de 51 a 200 & menos de 50 & 4 & 0.15 \\
\hline $\begin{array}{l}\text { Pendiente del } \\
\text { terreno (grados) }\end{array}$ & mayores a 45 & de 31 a 45 & de 16 a 30 & de 6 a 15 & de 0 a 5 & 5 & 0.1 \\
\hline
\end{tabular}

\subsection{Modelación de la red de conectividad}

La modelación de la red de conectividad se realiza mediante un modelo de sistema de información geográfica de costo-distancia para buscar las rutas de máxima conectividad entre las áreas protegidas sobre el mapa de resistencias al desplazamiento. El uso de estas funciones en este tipo de trabajos se ha empleado también en otras localidades de Latinoamérica, en los trabajos realizados por Murrieta (2005); Pinto y Keitt, (2009), y Rabinowitz y Zeller (2010). Se utiliza cada nodo como un punto de origen a conectar sobre la superficie de costos creada a cada punto de destino, y se generan redes de conectividad desde el nodo elegido como el origen hacia los nodos destino por las rutas con menor dificultad al desplazamiento. Con esto se traza una red de conectividad estructural utilizando cada uno de los nodos prioritarios.

Posteriormente, se reclasificaron los tipos de cobertura de uso del suelo, obtenidos a partir del mapa de uso del suelo del año 2014, el que fue actualizado a partir de imágenes satelitales Sentinel del año 2019 para obtener el mapa de cobertura del suelo usado en el análisis. Este mapa final se reclasifica en función de la categoría de dificultad al desplazamiento que representa, según los criterios expuestos en el Cuadro 1. En el Cuadro 2 se muestran los resultados del procedimiento.

\begin{tabular}{|c|c|c|c|c|c|}
\hline 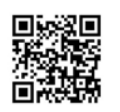 & (c) $\bigoplus_{\mathrm{BY}}\left(\mathrm{N}_{\mathrm{NC}}(\mathrm{SA}\right.$ & $\underset{\text { AMBIENALILS }}{3}$ & $\frac{1 \%}{2 \%}$ & 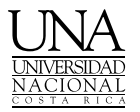 & 58 \\
\hline
\end{tabular}




\section{Revista de CIENCIAS AMBIENTALES Tropical Journal of Environmental Sciences}

Revista de Ciencias Ambientales (Trop J Environ Sci)

e-ISSN: 2215-3896

(Julio-Diciembre, 2020) . Vol 54(2): 51-67

DOI: https://doi.org/10.15359/rca.54-2.3

Open Access: www.revistas.una.ac.cr/ambientales e-mail: revista.ambientales@una.ac.cr Ramón-Puebla A., Yandy Rodríguez-Cueto Y. y Álvarez-Amargos P.

Cuadro 2. Agrupamiento de las coberturas del suelo acorde con las categorías propuestas en el Cuadro 1 Table 2. Grouping of the soil coverages according to the categories proposed in the Table 1

\begin{tabular}{|c|c|}
\hline Categorías de dificultad & Coberturas del suelo \\
\hline 1 Bosques naturales y poco antropizados & $\begin{array}{l}\text { Cobertura densa de bosque semideciduo micrófilo, mesófilo, } \\
\text { siempreverde y de bosques nublados, herbazal de ciénaga, manglares } \\
\text { y pinares. }\end{array}$ \\
\hline $\begin{array}{l}2 \text { Bosques y matorrales secundarios, plantaciones } \\
\text { forestales, cafetales y frutales }\end{array}$ & $\begin{array}{l}\text { Cafetales, cobertura de bosques pocos densos, arbustivos y ralos y } \\
\text { marabú. }\end{array}$ \\
\hline 3 Herbazales y pastizales con árboles aislados & Herbazales y pastizales con árboles aislados. \\
\hline $\begin{array}{l}4 \text { Cultivos varios, caña, arroz, granos y hortalizas y } \\
\text { otros cultivos temporales. }\end{array}$ & Cultivos temporales, tabaco, caña y arroz. \\
\hline $\begin{array}{l}5 \text { Terreno descubierto, áreas urbanas y grandes } \\
\text { superficies hídricas }\end{array}$ & $\begin{array}{l}\text { Suelo desnudo, suelo desnudo en zonas bajas y pantanosas, } \\
\text { superficies arenosas, desnudas naturales, desnuda antrópicas } \\
\text { (superficies construidas y carreteras) y superficies hídricas. }\end{array}$ \\
\hline
\end{tabular}

A continuación, se generaron las zonas de influencia para las componentes pertenecientes a la red vial y la red hídrica, a fin de determinar las regiones que cumplen con las distancias establecidas en los grados de dificultad al desplazamiento y se reclasifican dichas regiones en función de la escala establecida para estos dos componentes. Una vez obtenidas las reclasificaciones de las coberturas del suelo y las áreas de influencia de la red vial y la red hídrica, obtenidas estas dos últimas de GEOCUBA (2014), se transformaron a formato rasters empleando la herramienta Polygon to Raster, del software ArcMap de ESRI y utilizando la resolución espacial del raster correspondiente a las pendientes del terreno del área de estudio de $25 \times 25 \mathrm{~m}$.

Para generar la densidad de poblados se empleó la herramienta Point Density del software ArcMap de ESRI, cuyo resultado fue posteriormente reclasificado a los rangos de dificultad al desplazamiento establecidos en el Cuadro 1, mediante la aplicación de la herramienta Reclass. Este último procedimiento de reclasificación se utilizó también con las pendientes del terreno, acorde con los criterios del Cuadro 1. De esta forma, todos los componentes a incluir en el análisis se generaron en formato raster y se reclasificaron en valores entre 1 y 5 , que representan el grado de dificultad al desplazamiento para cada componente.

Los rasters creados para cada componente se suman algebraicamente para generar una superficie de fricción o dificultad al desplazamiento, en la cual el grado de fricción de un punto dado en el espacio corresponde a la sumatoria de los valores otorgados a cada uno de los indicadores de dificultad anteriormente descritos (ver Figura 3) y que simboliza, para el paso de las especies, el grado de resistencia o dificultad que el conjunto de factores impone a dichos desplazamientos.

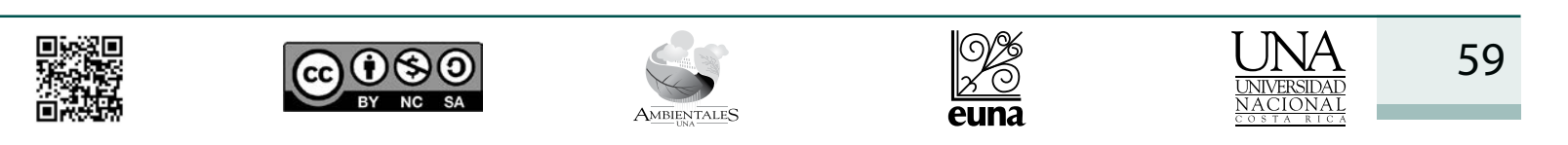




\section{Revista de CIENCIAS AMBIENTALES Tropical Journal of Environmental Sciences}

Revista de Ciencias Ambientales (Trop J Environ Sci) e-ISSN: 2215-3896

(Julio-Diciembre, 2020) . Vol 54(2): 51-67

DOI: https://doi.org/10.15359/rca.54-2.3

Open Access: www.revistas.una.ac.cr/ambientales e-mail: revista.ambientales@una.ac.cr Ramón-Puebla A., Yandy Rodríguez-Cueto Y. y Álvarez-Amargos P.

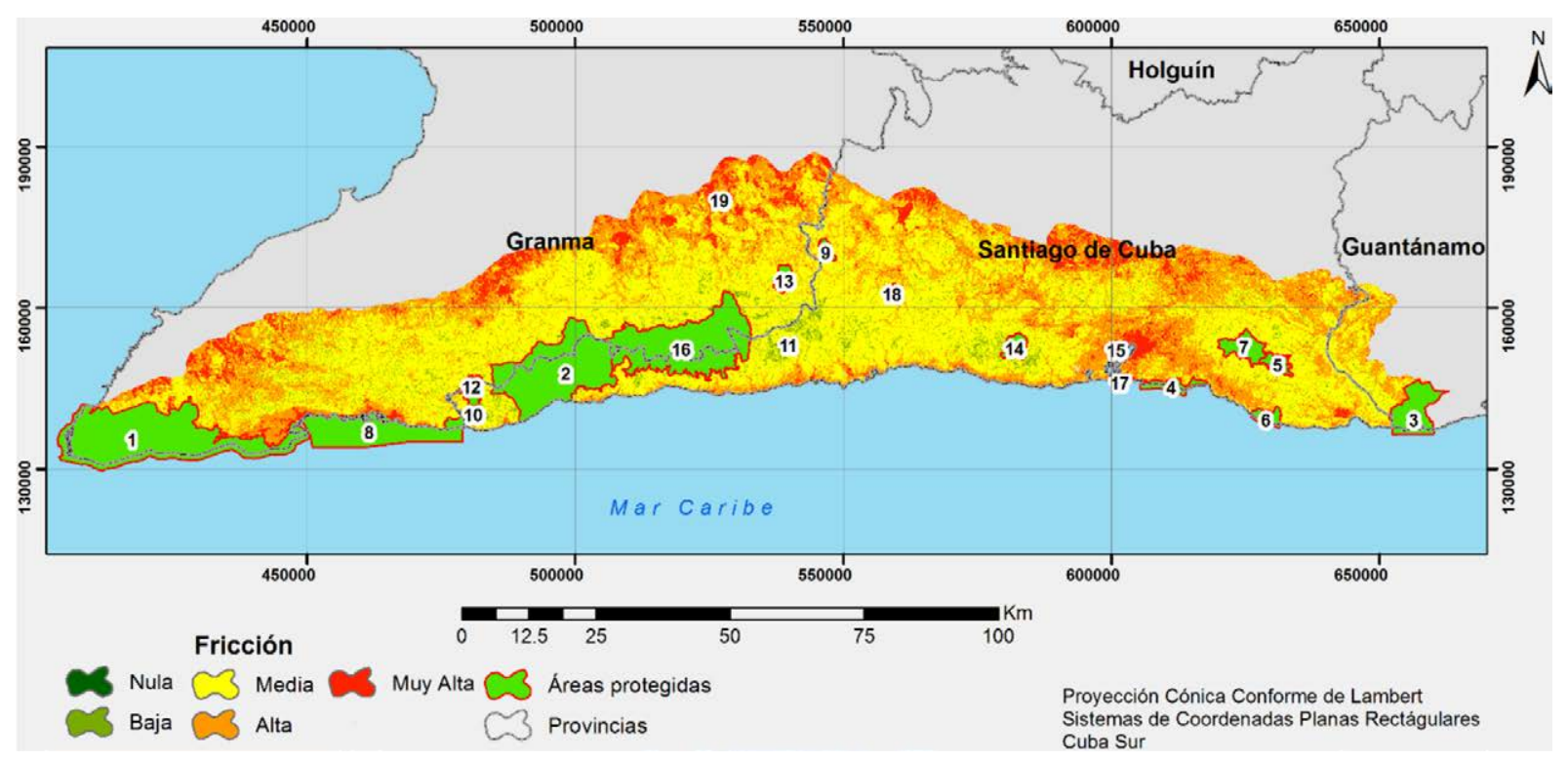

Figura 3. Dificultad de movimiento o fricción.

Figure 3. Difficulty of movement or friction.

El mapa de dificultad de movimiento o fricción se emplea seguidamente como fichero de entrada en las herramientas Cost Distance, Cost Back Link y Cost Path, de la extensión Spatial Analysis de ArcMap, para encontrar las rutas óptimas de desplazamiento entre cada una de las 19 áreas protegidas. Esto se fundamenta en una regla general que establece que cualquier línea debe conectar dos áreas protegidas, las cuales, a su vez, representan las áreas núcleo de dispersión para la biodiversidad. Por tanto, se propone que el ancho de las rutas sea de $100 \mathrm{~m}$, con base en los postulados de Hilty et al., (2007), que consideran este margen como una amplitud óptima para la movilidad de especies de aves de diferentes tamaños e historias de vida.

Posteriormente, se realizó la clasificación de las rutas de conectividad en altitudinales y longitudinales, en función de las siguientes características:

- Rutas de conectividad altitudinal: son las que unen las áreas protegidas ubicadas en las partes altas del macizo montañoso, que fueron establecidas como los puntos de llegada, y el resto de las áreas protegidas ubicadas en las partes bajas, que fueron establecidas como los puntos de salida.

- Rutas de conectividad longitudinal: son las que unen las diferentes áreas protegidas de una misma región altitudinal o similar tipo de formación vegetal.

Para la clasificación de las rutas en altitudinales o longitudinales, de acuerdo con la diferencia de altura y tipo de vegetación entre el punto de origen y destino de cada ruta, estas fueron

\begin{tabular}{|c|c|c|}
\hline 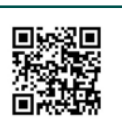 & (c) (1) @ (2) (2) & 60 \\
\hline
\end{tabular}




\section{Revista de CIENCIAS AMBIENTALES Tropical Journal of Environmental Sciences}

Revista de Ciencias Ambientales (Trop J Environ Sci) e-ISSN: 2215-3896

(Julio-Diciembre, 2020) . Vol 54(2): 51-67

DOI: https://doi.org/10.15359/rca.54-2.3 Open Access: www.revistas.una.ac.cr/ambientales e-mail: revista.ambientales@una.ac.cr Ramón-Puebla A., Yandy Rodríguez-Cueto Y.

intersectadas con el modelo digital de elevación, que se obtuvo a partir de las curvas de nivel de GEOCUBA (2014) y el mapa de vegetación natural y seminatural de Cuba, del Instituto de Ecología y Sistemática (2014). La categorización de las rutas tuvo como objetivos conocer, a partir de lo planteado por Bennett (2004), cuáles de éstas pueden ser utilizadas para suplir poblaciones en disminución, mejorar diversidad genética o recolonizar hábitats donde se han producido extinciones o disminuciones de especies por afectaciones de origen natural o antrópico (longitudinales); y cuáles pueden ser una opción de ruta migratoria hacia zonas más elevadas para contrarrestar el cambio de condiciones ecológicas por el cambio climático (altitudinales).

Todo este procedimiento anteriormente descrito para la modelación de la red de conectividad se realizó de forma automatizada a partir del esquema formulado por los autores (Figura 4), mediante la programación con el empleo del lenguaje Python para ArcGIS y la librearía arcpy de Python, el cual se corrió en el software ArcGIS 10.4.

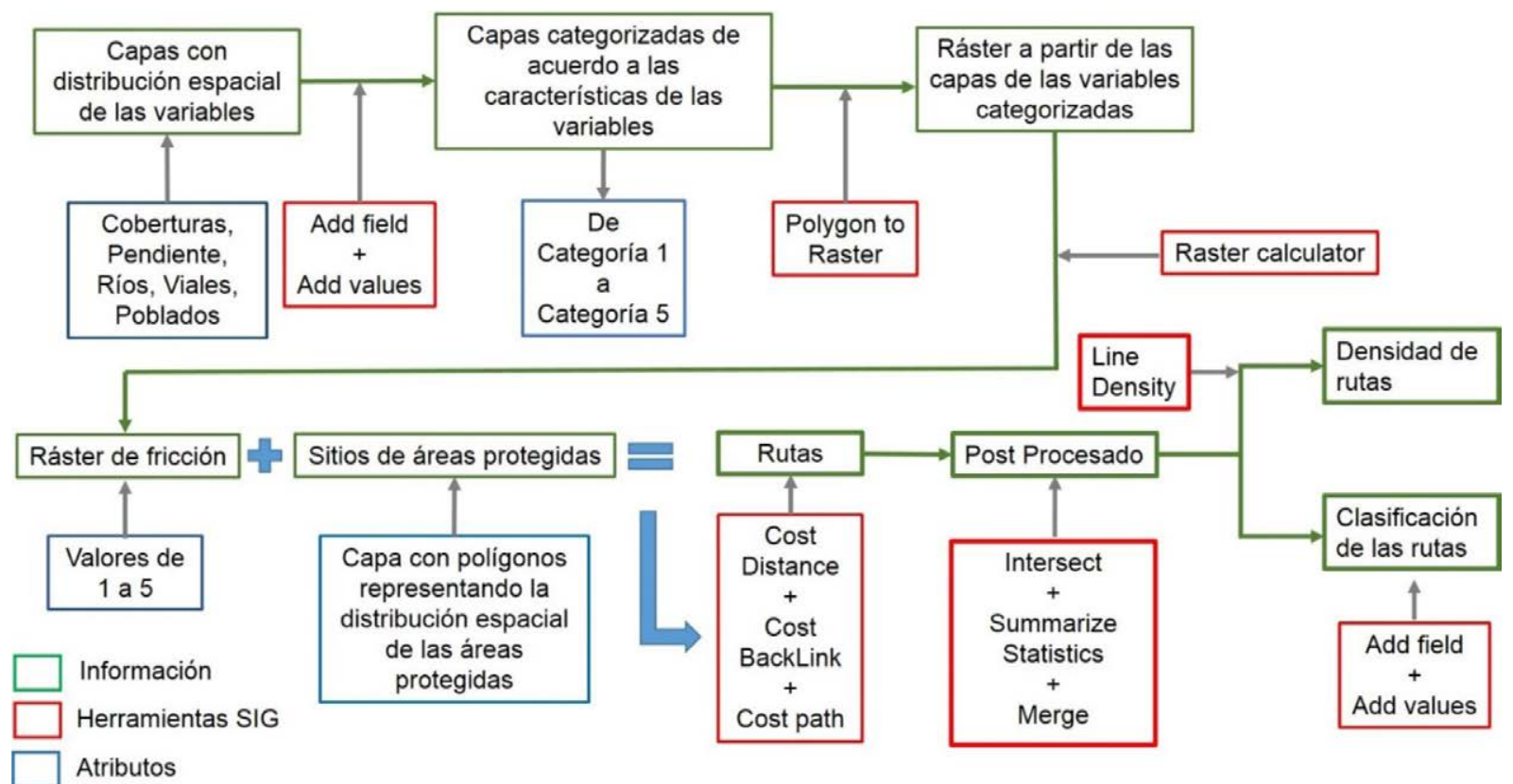

Figura 4. Esquema metodológico diseñado para obtener las rutas de conectividad.

Figure 4. Methodological scheme designed to obtain the connectivity routes.

\section{Resultados y discusión}

El ejercicio de modelación de la red de conectividad sobre el mapa de fricción al desplazamiento de las especies permitió obtener un total de 186 rutas de conectividad de diferente longitud, con un área total de $131.31 \mathrm{~km}^{2}$, lo que permite conectar, entre sí, cada una de las 19 áreas protegidas seleccionadas, $\mathrm{y}$ ofrecer, en algunos casos, varias alternativas de conectividad

\begin{tabular}{|c|c|c|}
\hline 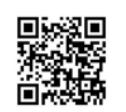 & (c) (i) (-) & 61 \\
\hline
\end{tabular}




\section{Revista de CIENCIAS AMBIENTALES Tropical Journal of Environmental Sciences}

Revista de Ciencias Ambientales (Trop J Environ Sci)

e-ISSN: 2215-3896

(Julio-Diciembre, 2020) . Vol 54(2): 51-67

DOI: https://doi.org/10.15359/rca.54-2.3

Open Access: www.revistas.una.ac.cr/ambientales e-mail: revista.ambientales@una.ac.cr Ramón-Puebla A., Yandy Rodríguez-Cueto Y.

entre las áreas (Figura 5). Ello brinda una variada gama de opciones para el trazado de posibles corredores biológicos de acuerdo con las condiciones más favorables, intereses comunitarios y gubernamentales.

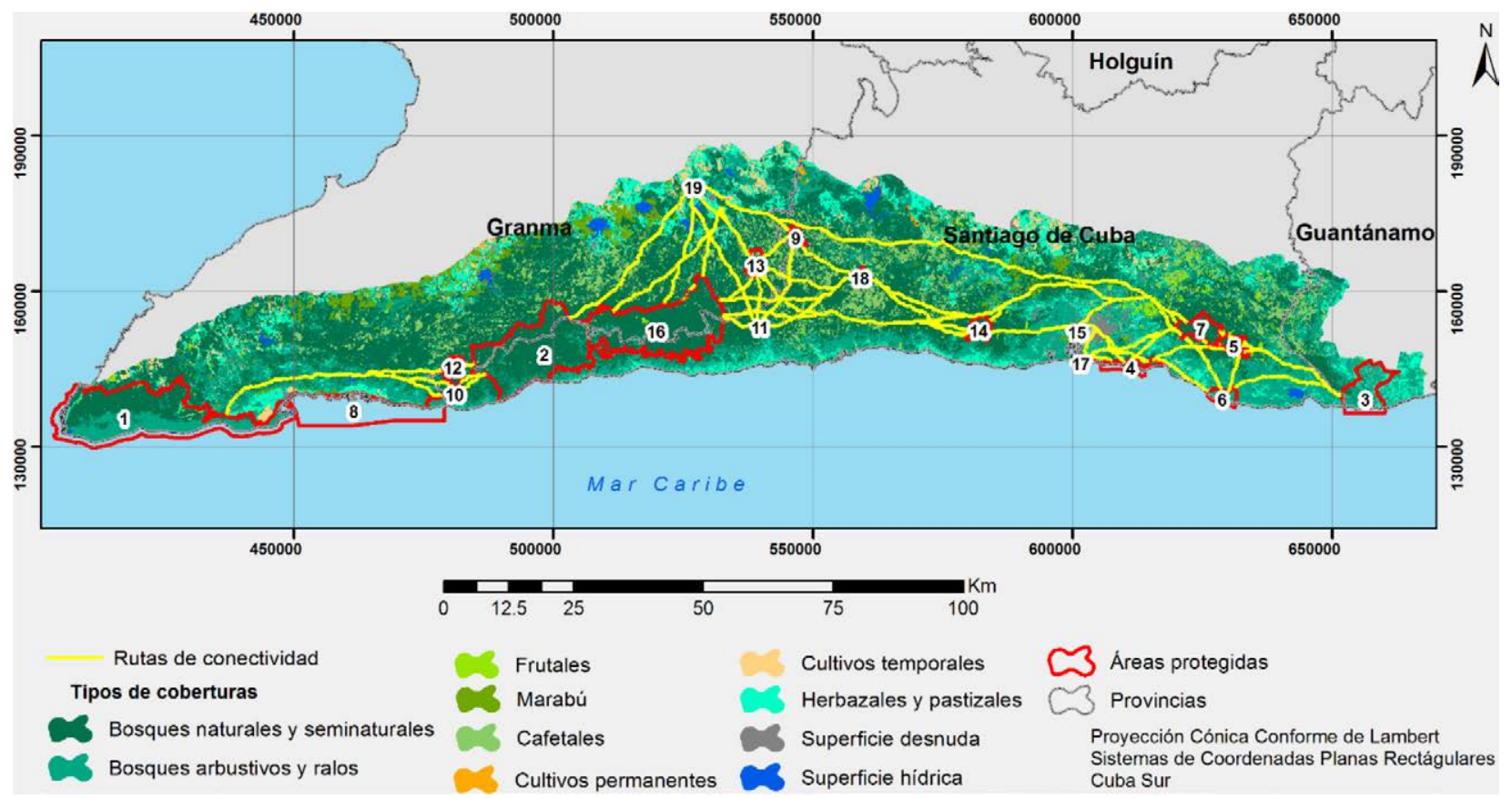

Figura 5. Rutas de conectividad.

Figure 5. Connectivity routes.

La clasificación de dichas rutas arrojó que el 62 \% de las rutas (114) pueden clasificarse en rutas de conectividad altitudinal, que permiten la conexión entre áreas protegidas y parches de bosques a diferentes pisos altitudinales; mientras que el $38 \%$ (72) pueden categorizarse como de conectividad longitudinal, pues pueden conectar entre áreas protegidas y parches de bosques a un mismo nivel altitudinal. En el (Cuadro 3) se muestra la relación de rutas de conectividad altitudinal (A) y longitudinal (L), así como las rutas de conexión entre áreas protegidas.

Cuadro 3. Clasificación de las rutas en altitudinales y longitudinales

Table 3. Routes classification in altitudinal and longitudinal

\begin{tabular}{lccccccccccccccccccc}
\hline Identificador $^{*}$ & $\mathbf{1}$ & $\mathbf{2}$ & $\mathbf{3}$ & $\mathbf{4}$ & $\mathbf{5}$ & $\mathbf{6}$ & $\mathbf{7}$ & $\mathbf{8}$ & $\mathbf{9}$ & $\mathbf{1 0}$ & $\mathbf{1 1}$ & $\mathbf{1 2}$ & $\mathbf{1 3}$ & $\mathbf{1 4}$ & $\mathbf{1 5}$ & $\mathbf{1 6}$ & $\mathbf{1 7}$ & $\mathbf{1 8}$ & $\mathbf{1 9}$ \\
\hline $\mathbf{1}$ & - & L & A & L & A & A & A & L & L & A & A & L & A & A & L & L & L & L & L \\
$\mathbf{2}$ & - & - & A & A & L & A & L & L & L & A & L & A & A & A & A & & A & A & A \\
$\mathbf{3}$ & - & - & - & A & A & L & L & A & L & A & A & A & A & A & A & A & L & A & L \\
$\mathbf{4}$ & - & - & - & - & A & L & A & L & A & A & A & A & A & A & A & A & L & L & L \\
$\mathbf{5}$ & - & - & - & - & - & A & - & A & A & L & L & A & L & L & A & L & A & L & A
\end{tabular}




\section{Revista de CIENCIAS AMBIENTALES Tropical Journal of Environmental Sciences}

Revista de Ciencias Ambientales (Trop J Environ Sci) e-ISSN: 2215-3896

(Julio-Diciembre, 2020) . Vol 54(2): 51-67

DOI: https://doi.org/10.15359/rca.54-2.3

Open Access: www.revistas.una.ac.cr/ambientales e-mail: revista.ambientales@una.ac.cr Ramón-Puebla A., Yandy Rodríguez-Cueto Y. y Álvarez-Amargos P.

\begin{tabular}{lccccccccccccccccccc}
\hline Identificador $^{*}$ & 1 & 2 & 3 & 4 & $\mathbf{5}$ & $\mathbf{6}$ & $\mathbf{7}$ & $\mathbf{8}$ & $\mathbf{9}$ & $\mathbf{1 0}$ & $\mathbf{1 1}$ & $\mathbf{1 2}$ & $\mathbf{1 3}$ & $\mathbf{1 4}$ & $\mathbf{1 5}$ & $\mathbf{1 6}$ & $\mathbf{1 7}$ & $\mathbf{1 8}$ & $\mathbf{1 9}$ \\
\hline $\mathbf{6}$ & - & - & - & - & - & - & L & A & L & A & A & A & A & A & L & A & L & A & L \\
7 & - & - & - & - & - & - & - & A & L & L & L & A & A & L & A & L & A & L & L \\
8 & - & - & - & - & - & - & - & - & A & A & A & A & A & A & L & A & L & L & A \\
9 & - & - & - & - & - & - & - & - & - & L & L & A & L & L & A & L & A & A & L \\
10 & - & - & - & - & - & - & - & - & - & - & L & L & A & A & A & L & A & A & A \\
11 & - & - & - & - & - & - & - & - & - & - & - & A & L & A & A & L & A & A & A \\
12 & - & - & - & - & - & - & - & - & - & - & - & - & A & L & A & A & A & A & A \\
13 & - & - & - & - & - & - & - & - & - & - & - & - & - & L & A & A & A & L & A \\
14 & - & - & - & - & - & - & - & - & - & - & - & - & - & - & A & A & A & A & A \\
15 & - & - & - & - & - & - & - & - & - & - & - & - & - & - & - & A & A & L & L \\
16 & - & - & - & - & - & - & - & - & - & - & - & - & - & - & - & - & A & A & A \\
17 & - & - & - & - & - & - & - & - & - & - & - & - & - & - & - & - & - & L & L \\
18 & - & - & - & - & - & - & - & - & - & - & - & - & - & - & - & - & - & - & A \\
19 & - & - & - & - & - & - & - & - & - & - & - & - & - & - & - & - & - & - & - \\
\hline
\end{tabular}

* 1.Parque Nacional Desembarco del Granma, 2. Parque Nacional Turquino, 3.Reserva Ecológica Hatibonico, 4. Reserva Ecológica Siboney-Juticí, 5. Reserva Ecológica Pico Mogote, 6. Reserva Natural El Retiro, 7.Paisaje Natural Protegido Gran Piedra, 8.Reserva Ecológica El Macío, 9. Reserva Florística Manejada Pozo Prieto, 10.Reserva Florística Manejada Caraquitas, 11. Elemento Natural Destacado Salto de Alcarraza, 12.Reserva Ecológica Pico Caracas, 13. Reserva Ecológica El Gigante, 14.Reserva Florística Manejada Loma del Gato-Monte Líbano, 15.Refugio de Fauna San Miguel de Parada, 16. Parque Nacional Pico La Bayamesa, 17. Paisaje Natural Protegido Estrella-Aguadores, 18. Reserva Florística Manejada Monte Bisse, 19. Reserva Florística Manejada Monte Natural Cupeinicú.

El Cuadro 3 muestra que el área protegida a la que más rutas llegan es al Parque Nacional Pico La Bayamesa con 84; seguido del Parque Nacional Turquino y el Paisaje Natural Gran Piedra, con 79 y 58 respectivamente. Estas fueron las áreas ubicadas hipsométricamente a mayor altitud en la región; por lo que se podría afirmar que estas pueden ser potenciales rutas migratorias hacia zonas más elevadas para las especies que busquen contrarrestar el cambio de condiciones ecológicas por el aumento de las temperaturas, debido el cambio climático.

Es importante resaltar la presencia de 53 zonas de cruces en las rutas de conectividad, señaladas como zonas de interés (Figura 6) que, según Kellman et al., (1998), son indicativos de zonas importantes para la biodiversidad y para el sostenimiento a largo plazo de la red ecológica y de los procesos biológicos inherentes a ella, pues pueden promover el mantenimiento de varias fuentes y sumideros de poblaciones de flora y fauna en fragmentos de bosque entre áreas protegidas. Estas 53 zonas coincidieron, en muchos casos, con fragmentos de bosques, los cuales, por su tamaño y salud, no han sido incluidos dentro del Sistema de Áreas Protegidas y con otras 3 zonas, coincidentes con la mayor densidad de puntos en el mapa, que se valoran por parte de la Junta Coordinadora de Áreas Protegidas de la provincia Granma como nuevas posibles propuestas de áreas protegidas, por su elevado nivel de conservación de la cobertura natural.

\begin{tabular}{|c|c|c|}
\hline 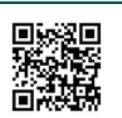 & (c) (i) (2) (2) & 63 \\
\hline
\end{tabular}




\section{Revista de CIENCIAS AMBIENTALES Tropical Journal of Environmental Sciences}

Revista de Ciencias Ambientales (Trop J Environ Sci) e-ISSN: 2215-3896

(Julio-Diciembre, 2020) . Vol 54(2): 51-67

DOI: https://doi.org/10.15359/rca.54-2.3

Open Access: www.revistas.una.ac.cr/ambientales e-mail: revista.ambientales@una.ac.cr Ramón-Puebla A., Yandy Rodríguez-Cueto Y. y Álvarez-Amargos P.

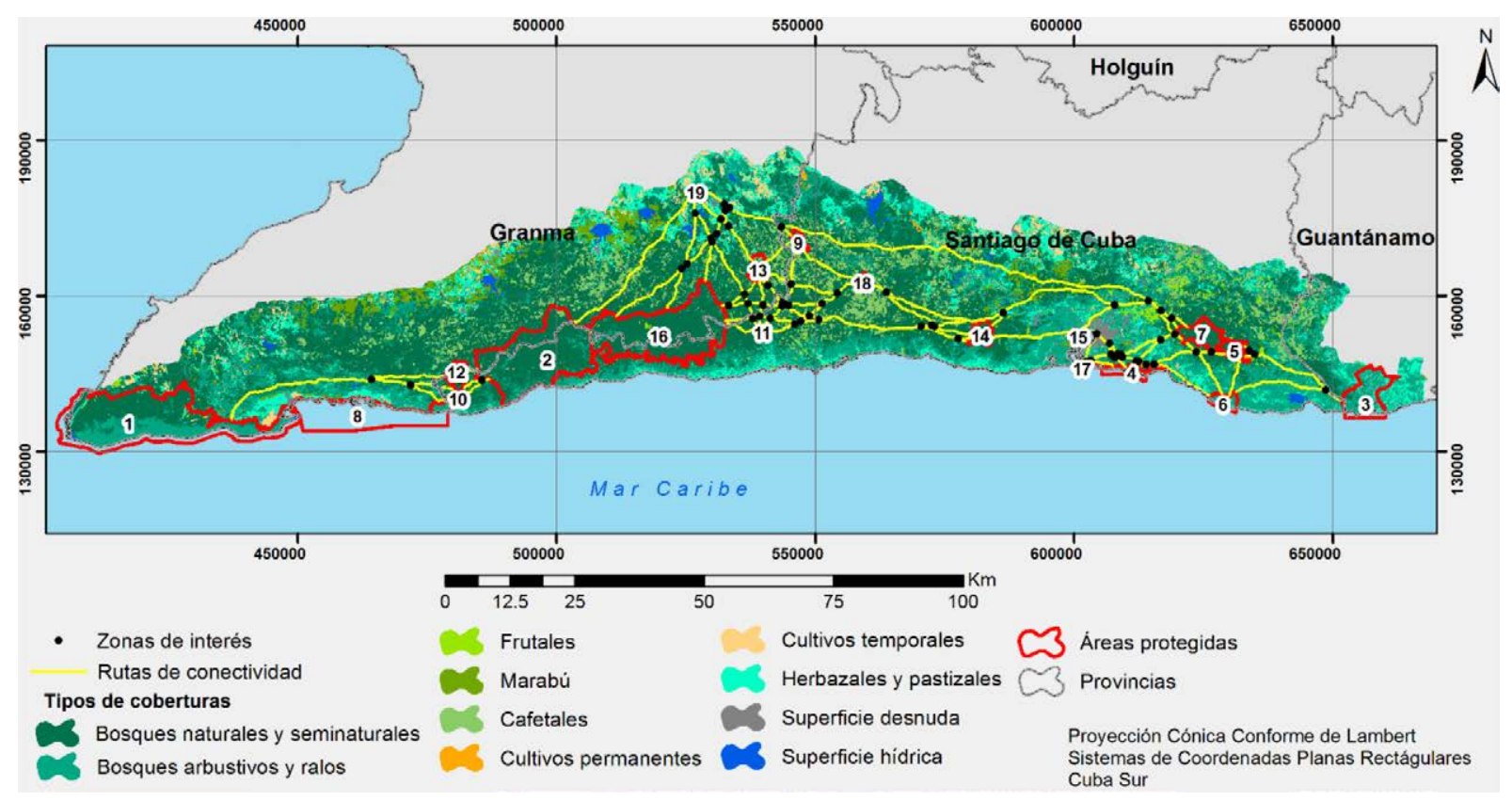

Figura 6. Puntos de cruces de las rutas de conectividad.

Figure 6. Crossings points of connectivity routes.

En el caso de los fragmentos pequeños de bosques que coinciden con zonas de cruces; estas áreas, a pesar de no ser capaces de mantener poblaciones viables de especies por sus dimensiones, son fundamentales para restablecer la conectividad a lo largo del paisaje, sobre todo en las rutas más extensas. Por tanto, debe de prestárseles especial atención por parte de los organismos correspondientes en las acciones de planificación territorial.

\section{Conclusiones}

El área de estudio consiste en una zona de $7155.27 \mathrm{~km}^{2}$ divididos en cobertura boscosa fragmentada (56 \%) y una matriz agropecuaria-urbana heterogénea y de amplitud territorial considerable ( $44 \%$ ). Mediante la propuesta de conectividad estructural se plantea la recuperación de un total de $8722 \mathrm{~km}^{2}$ de zonas con algún nivel de degradación de la cobertura vegetal, con el propósito de contribuir a la restauración de la conectividad de los fragmentos de cobertura boscosa, el mejoramiento del hábitat terrestre para los elementos bióticos del paisaje, la disminución de los efectos negativos de la fragmentación y la conservación de la biodiversidad.

La metodología diseñada para la definición de las rutas de conectividad constituye una novedad para Cuba. Ésta se basa en el análisis un grupo de cinco factores: cobertura de uso del suelo, hidrografía, densidad de poblados y cantidad de habitantes, red vial y pendientes; recoge la mayoría de los elementos que pueden incidir en la conectividad de espacios naturales a nivel

\begin{tabular}{|c|c|c|}
\hline 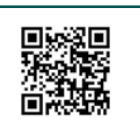 & (c) (1) @ (2) (2) & 64 \\
\hline
\end{tabular}




\section{Revista de CIENCIAS AMBIENTALES Tropical Journal of Environmental Sciences}

Revista de Ciencias Ambientales (Trop J Environ Sci) e-ISSN: 2215-3896

(Julio-Diciembre, 2020) . Vol 54(2): 51-67 DOI: https://doi.org/10.15359/rca.54-2.3 Open Access: www.revistas.una.ac.cr/ambientales e-mail: revista.ambientales@una.ac.cr Ramón-Puebla A., Yandy Rodríguez-Cueto Y. y Álvarez-Amargos P.

local y regional y, en este sentido, permite la identificación de rutas idóneas, con lo cual puede contribuir a las tareas de planificación y ordenamiento territorial.

La aplicación de la metodología generó un total de 186 enlaces de conectividad estructural, muchos de estos coincidentes, espacialmente. Ello refuerza la importancia de estas rutas que permitirían mejorar, paulatinamente, las funciones y procesos ecológicos propios de los bosques de estas áreas protegidas. Además, reconoció 53 zonas de interés que constituyen, en su mayoría, fragmentos de bosques que, de otra forma, quedarían aislados.

La clasificación de las rutas en altitudinales (114) y longitudinales (72) muestra un claro predominio de las primeras, lo cual evidencia que las áreas protegidas a las que más rutas llegan son las ubicadas hipsométricamente a mayores alturas en la región montañosa. Esto les da la posibilidad de constituirse en rutas migratorias potenciales para especies que busquen contrarrestar el cambio de condiciones ecológicas por el cambio climático.

Finalmente, corresponde a especialistas en biodiversidad y ecología analizar estas potenciales rutas de conectividad y la factibilidad de cada una de ellas para la propuesta de corredores biológicos para el sistema de áreas protegidas de la Sierra Maestra. Si bien esta propuesta corresponde, de forma general, a elementos bióticos del paisaje, la metodología empleada puede ser adaptada a otros tipos de hábitats y especímenes, así como a especies o grupos funcionales de especies asociadas a ecosistemas boscosos, con tan solo el ajuste del ancho de los corredores ecológicos y las variables que requieran las especies para desarrollar sus hábitats.

\section{5. Ética y conflicto de intereses}

Las personas autoras declaran que han cumplido totalmente con todos los requisitos éticos y legales pertinentes, tanto durante el estudio como en la producción del manuscrito; que no hay conflictos de intereses de ningún tipo; que todas las fuentes financieras se mencionan completa y claramente en la sección de agradecimientos; y que están totalmente de acuerdo con la versión final editada del artículo.

\section{Agradecimientos}

A la Revista y las personas revisoras anónimas por sus oportunos comentarios a la versión final del escrito.

\section{Referencias}

Arias, E., Chacón, O., Herrera, B., Induni, G., Heiner, A., Coto, M. y Barborak, J. (2008). Las redes de conectividad como base para la planificación de la conservación de la biodiversidad: Propuesta para Costa Rica. Recursos Naturales y Ambiente, 54, 37-43.

Bennett, A. (2004). Enlazando el paisaje: El papel de los corredores y la conectividad en la conservación de la vida silvestre. UICN.

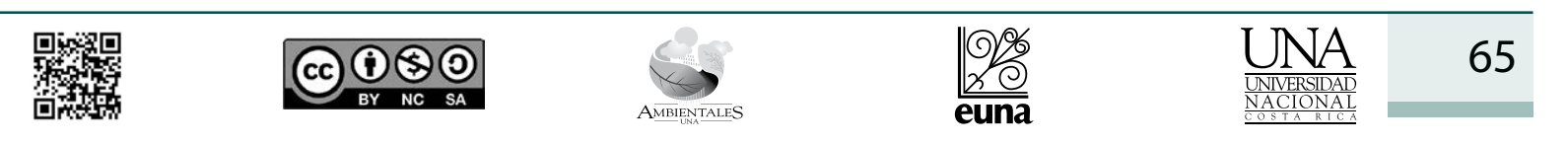




\section{Revista de CIENCIAS AMBIENTALES Tropical Journal of Environmental Sciences}

Revista de Ciencias Ambientales (Trop J Environ Sci) e-ISSN: 2215-3896

(Julio-Diciembre, 2020) . Vol 54(2): 51-67 DOI: https://doi.org/10.15359/rca.54-2.3 Open Access: www.revistas.una.ac.cr/ambientales e-mail: revista.ambientales@una.ac.cr Ramón-Puebla A., Yandy Rodríguez-Cueto Y. y Álvarez-Amargos P.

Bennett, G. y Molungoy, K. (2006). Review of experience with ecological networks, corridors and buffer zones. Secretariat of the Convention on Biological Diversity. Technical Series No. 23.

Borroto-Páez, R. y Mancina, C. (2011). Mamíferos en Cuba. UPC Print.

Céspedes, M. V., Delgado, D., Velásquez, S., Herrera Fernández, B., Finegan, B., y Campos Arce, J. (2008). Diseño de una red ecológica de conservación entre la Reserva de Biosfera La Amistad y las áreas protegidas del Área de Conservación Osa, Costa Rica. Recursos Naturales y Ambiente (CATIE), 54, 44-50.

Chacón, N. (2016). Rutas de conectividad entre las áreas protegidas del área de conservación Arenal-Tempisque bajo diferentes escenarios de cambio climático [Tesis de Maestría inédita], Universidad Nacional Heredia, Costa Rica.

EUROPAC (2009). Programa de trabajo para las áreas protegidas 2009-2013. Conectividad ecológica y áreas protegidas, herramientas y casos prácticos. EUROPAC.

GEOCUBA. (2018). División político-administrativa de la República de Cuba. [Shapefile de ArcGIS]. GEOCUBA

GEOCUBA. (2014). Mapa topográfico de la República de Cuba. [Shapefiles de ArcGIS]. GEOCUBA

Hilty, J., Zander, W., y Merenlender, A. (2007). Corridor ecology: the science and practice of linking landscapes for biodiversity conservation. Island Press.

Hoctor, T., Carr, M. y Zwick, P. (1999). Identifying a linked reserve system using a regional landscape approach: The Florida ecological network. Conservation Biology, 14(4), 984-1000. https://doi.org/10.1016/j.biocon.2010.01.002

Instituto de Ecología y Sistemática. (2014). Mapa de vegetación natural y seminatural de Cuba. [Shapefile de ArcGIS]. Estrada, R. y Capote, R.

Jiménez, G. (2001). Propuesta metodológica para el diseño y validación de corredores biológicos en Costa Rica. Revista Forestal Centroamericana, 34, 73-79.

Kellman, M., Tackaberry, R., y Rigg, L. (1998). Structure and function in two tropical gallery forest communities: implications for forest conservation in fragmented systems. Journal of Applied Ecology, 35(2), 195-206. https://doi.org/10.1046/j.1365-2664.1998.00300.x

MacArthur, R. y Wilson, E. O. (1967). The theory of island biogeography. Princeton University Press.

Mancina, C. y Cruz, D. (Eds.). (2017). Diversidad biológica de Cuba. Métodos de inventario, monitoreos y colecciones biológicas. Instituto Nacional de Ecología y Sistemática.

Miller, K., Chang, E. y Jhonson, N. (2001). En busca de un enfoque común para el Corredor Biológico Mesoamericano. World Resources Institute

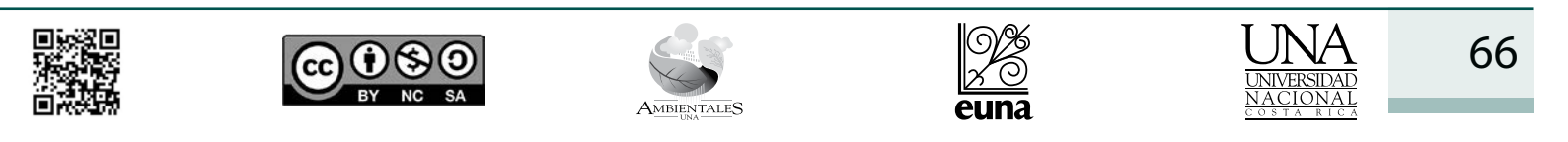




\section{Revista de CIENCIAS AMBIENTALES Tropical Journal of Environmental Sciences}

Murrieta A. (2005). Caracterización de cobertura vegetal y propuesta de una red de conectividad ecológica en el Corredor Biológico Volcánica Central-Talamanca [Tesis de Maestría inédita], CATIE, Costa Rica.

Noss, R. (1991). Landscape connectivity: different functions at different scales. Island Press.

Parrish, J., Braun, D. y Unnasch, R. (2003). Are we conserving what we say we are? Measuring ecological integrity within protected areas. Bioscience, 53(9), 851-860. https://doi.org/10.164 1/0006-3568(2003)053[0851:AWCWWS]2.0.CO;2

Pinto, N., y Keitt, T. (2009). Beyond the least-cost path: evaluating corridor redundancy using a graph-theoretic approach. Landscape Ecology, 24(2), 253-266. https://doi.org/10.1007/ s10980-008-9303-y

Primack, R., R. Rozzi, P. Feinsinger, R. Dirzo F. y Massardo (Eds.). (2001). Fundamentos de conservación biológica: Perspectivas latinoamericanas. Fondo de Cultura Económica.

Rabinowitz, A., y Zeller, K. (2010). A range-wide model of landscape connectivity and conservation for the jaguar, Panthera onca. Biological conservation, 143(4), 939-945. https://doi. org/10.1016/j.biocon.2010.01.002

Viña, N., Viña, N., Mustelier, K., Trapero y Vicario, A. (2000). Caracterización físico-geográfica del macizo Sierra Maestra. BIOECO.

\begin{tabular}{|c|c|c|}
\hline 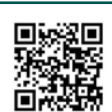 & 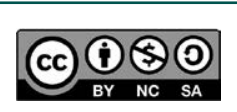 & 67 \\
\hline
\end{tabular}

